\title{
Boundary Crossing Creativity in the Design of Digital Resources for Teaching and Learning about Climate Change
}

\author{
Chronis Kynigos'1, and Maria Daskolia² \\ 1 Educational Technology Lab, Dept. of Educational Studies, School of Philosophy, National and Kapodistrian University of Athens, Greece \\ 2 Environmental Education Lab, Dept. of Educational Studies, School of Philosophy, National and Kapodistrian University of Athens, Greece
}

\begin{abstract}
We approach creativity in educational design with teachers working together in interdisciplinary communities of practice to develop resources for teaching and learning about climate change in formal school settings. We address climate change as a socio-scientific 'wicked problem' and discuss the notion of creativity in educational design in a context of transformative intervention in education leading away from silo academic domain paradigms. We perceived the resources as boundary objects during the process of communication and joint design by the diverse community members. Our interest focused on studying the boundary crossing processes which facilitated creative ideas to come out, selected and transcribed into the actual resources designed. Critical episode analysis showed that boundary crossing mechanisms were employed in the interactions among the educational designers aided by and in interaction with digital media supporting collaboration. These socio-technical interactions functioned as an empowered professional learning and working milieu, within which creative processes and outcomes were nurtured. In particular, educational designers, along with trying to frame climate change as a wicked problem, attempted to ad-
\end{abstract}

\section{Article history:}

Received: May 10, 2021

Received in revised from: June 29, 2021

Accepted: July 5, 2021

ISSN 2354-0036

DOI: $10.2478 /$ ctra-2021-0013 dress the challenging issue of designing a creative educational resource on this topic. Our research suggests that boundary crossing creativity in interdisciplinary teams of educational designers can be an answer to not only how to focus learning on addressing the grand wicked problems of our times, but also how to deal with the multiple challenges arising from educational design per se.

\section{KEYWORDS:}

boundary crossing, creativity, education, resource design, digital media, socio-technical environments, climate change

\author{
Corresponding author at: \\ Chronis Kynigos \\ E-MAIL: kynigos@eds.uoa.gr
}




\section{INTRODUCTION}

Promoting social creativity in interdisciplinary contexts to support collaborative design practices has recently been identified as a prominent trend across many sectors (Darbellay, Moody, \& Lubart, 2017). In this paper we focus on the education sector where increased transformational forces place professionals as well as students in a position demanding reflection and re-appraisal of their role and in developing new skills and competences. Creativity together with collaboration and problem-solving are highlighted as key meta-knowledge competences that enable educational designers, teachers and of course students to act on their disciplinary knowledge and develop new forms of personal and collective knowledge about a rapidly changing world (Kereluik et al., 2013). Channeling the cultivation of such skills in education is crucial since they are underlined as necessary to support the transition to new ways of thinking, learning and addressing many of the current and challenging environmental and sustainability challenges of our times (NewmanStoren, 2014; Sharp et al., 2021). Teaching and learning about these challenges requires all parties concerned to develop the appropriate dispositions and competences.

Education is par excellence a niche where creativity can be fostered to empower people, youths in particular, to address complex socio-scientific issues, which have also been called 'wicked problems'. In this paper, we will consider climate change as a typical case of a wicked problem, an environmental sustainability challenge (UNESCO, 2017). In the education sector with a long tradition of silo approaches to academic domains, issues such as addressing climate change have to be embedded in a transformational context leading to an educational paradigm shift (Wals, 2015). Climate change is a sustainability challenge involving diverse risks and harmful impacts to human-nature life systems (Hansen \& Stone, 2016). It is a wicked problem, i.e. a trans-disciplinary, ill-defined, and contentious real-life issue, with no universal agreement over its consequences let alone solutions. Dealing with it asks for concrete, expert-based mitigation and adaptation measures on a local, national and international level. However, it also necessitates changes in the conventional modes of thinking and in business-as-usual practices. To this end, fostering creativity, collaboration and interdisciplinary problem-solving in education are important prerequisites for 'changing mindsets, not the climate', as the communication message by UNESCO (2017) clearly echoes.

In the study reported here, we focus on a special kind of creativity, which we define as 'boundary crossing creativity', one which emerges in diverse groups coming together to perform a demanding shared task, such as to co-design novel educational resources and services. We studied its emergence when educational professionals with diverse disciplinary backgrounds got together to co-design teaching resources for school students and thus engaged in interdisciplinary problem-solving in the context of an educational design problem: how to engage students to address the wicked problem of climate change. We view interactions in interdisciplinary professional communities of practice as a context within which creative processes and products may occur, affecting both designers and students as users of the design productions, while also leading to more transformational designs and paradigm shifts in education at large. Along this line, 
we brought together such diverse groups in a joint enterprise to design and develop innovative teaching and learning digital resources on the sustainability issue of climate change. We were particularly interested in studying how their engagement in boundary crossing processes, such as the exchange of ideas, views and suggestions over their joint endeavor and resources as artifacts design led them to creative designs.

\section{FROM SOCIAL CREATIVITY TO BOUNDARY CROSSING CREATIVITY}

It has been a while since the study of creativity has considerably broadened from pertaining only to some few and gifted individuals and their unique and groundbreaking works to the creative processes taking place in collectives, within social, cultural and organizational contexts that allow for more 'local' and collaborative outcomes to emerge and be appreciated as creative (Daskolia et al., 2012; Glăveanu, 2015). Without minimizing the contribution of 'individual creativities', sociocultural approaches to creativity seem to provide a very promising terrain to better understand and nurture creativity in more holistic ways (Glăveanu, 2020). To identify and understand such creativity it is important to consider the tools used for interaction for humans to communicate about also as objects (resources) under design.

In particular, Fischer's theory of social creativity (Fischer, 2005) emanates from a problemsolving standpoint to contend that there are limits in the ways individuals can address a specific problem or situation, especially when complexity is an inherent feature of it. It thus needs "the synergy of many" to activate less conventional and more appropriate thinking processes to approach complex problems, such as design problems. The theory emphasizes in particular that, when in collectives, each individual brings along their own 'socio-cultural' capital - in terms of their educational and disciplinary background, life experiences and/or professional expertise, as well as the cultural and epistemological antecedents of all these -, which is voiced in his/her distinctive perspective towards addressing a particular problem or situation. It is the actual processes and outcomes of mingling the individual perspectives that leads to the co-construction of a new, shared and more enriched perspective of the problem at stake (John-Steiner, 2000).

Heterogeneity and interdisciplinarity are thus the sine-qua-non qualities of a creative collective of people who come together in a community to jointly address a particular problem of common concern. 'Communities of Interest', a core construct of the theory of social creativity, are made of representatives of diverse communities of practice, i.e., communities of practitioners in particular domains who undertake a similar work (Lave \& Wenger, 1991; Wenger, 1998). However, when they become members of a 'community of interest' (Col), their diverse 'activity systems' in terms of disciplinary knowledge, professional expertise and epistemological perspectives often lead to confrontational situations. Col members face communication obstacles in order to develop shared understandings over the task-at-hand, which can be shaped into opportunities for exchange and integration and conditions for creative thinking (Arias et al., 2000). 
Social creativity is manifested and can be nurtured in a social context, among community members whose diverse perspectives are met and merged (Engeström, 2001), but also with the aid of appropriate technologies and tools (Glăveanu et al., 2020). A necessary condition for social creativity is thus the existence of a 'socio-technical environment', that is an appropriate and purposefully designed milieu, consisting of a community of individuals whose creative performance is facilitated and/or boosted within a particular 'technical' environment aiming to amplify the outcome of their collaborative efforts towards fulfilling the task at stake (Fischer et al., 2005). As far as the technological dimension is concerned, socio-technical environments for social creativity are equipped with digital interfaces and tools with a potential of empowering the Col members in their joint task by providing them with media to communicate, express themselves and engage in joint activities over complex and open-ended problems of mutual interest (Fischer, 2004; Fischer, 2005). 'Socio-technical environment' as a term is used to express the close interaction between the 'social' and the 'technical' dimensions of the world which surrounds and interacts with an individual or a group and which are equally important in eliciting, guiding and supporting creative thinking and new or innovative productions.

In our work leading to this research (see for example, Daskolia et al, 2016; Daskolia et al., 2018) we have found it most useful to connect Fischer's (2005) approach to social creativity with many concepts and ideas developed and proposed within the context of the Boundary Crossing theory by Akkerman \& Bakker (2011). According to the latter, individuals act within the 'boundaries' of their activity system, circumscribed by a set of values, norms and practices that influence their meanings, interactions and relationships. A mathematics teacher for example would only consider providing students with problems designed for them to handle and which do have a solution and only one at that. This is hardly the case with a practitioner in environmental education, who is expected to think and teach in terms of current complex environmental and sustainability issues, which are never easy to grasp, learn and handle. However, these boundaries, defined as the "sociocultural differences that give rise to discontinuities in action and interaction" (Akkerman \& Bakker, 2011, p. 139), can be transformed from potential barriers to potential resources for establishing communication, collaboration, and learning. They can thus become springboards for creative thinking and learning (Glăveanu \& Beghetto, 2017).

Boundary crossing processes are mostly expected to take place in professional domains with a high degree of specialization and a need for interdisciplinary and cross-sectional work. A range of 'boundaries' are thus met in educational resource design among teachers with different degrees of knowledge, different roles or cultural backgrounds. Among the strategies to mitigate the barriers set and the challenges involved by the perspectives of different individuals who are working together towards a shared goal, Fischer (2013) proposes interdisciplinary collaboration, the development of 'boundary objects', the engagement of knowledge brokers, and the use of new media supporting effective information flow.

In this paper, we coin the term 'boundary crossing creativity' as a descriptive frame to define social creativity arising from the boundary crossing processes that take place among professionals 
who interact within specially engineered socio-technical environments. Boundary crossing is put forward as an appropriate construct and as a broader metaphor to frame and study the complex, bidirectional and dynamic efforts by people in a socio-cultural situation and type of encounter. Boundary crossing creativity arises from the purposeful efforts of individuals or groups who stand 'at the boundaries' to establish or restore some kind of continuity in action or interaction across their practices (Bakker \& Akkerman, 2014). It lines up with the extension of these boundaries beyond the in-field space to an out-of-field space (Star, 1989), through negotiation and the combination of ingredients from different contexts (Engeström, Engeström, \& Kärkkäinen, 1995, p. 319).

Boundary crossing creativity rests on the idea that a socially situated creative work, as the locus of production of new knowledge in addressing a problem, requires the transcendence of the boundaries raised between heterogeneous people, communities and domains. These boundaries are not only disciplinary but also related to individual professional capital, developed norms and stances towards education and the transformations inherent in the sector. The very existence of boundaries entails an inherent creative potential which lies "where the unexpected can be expected, where innovative and unorthodox solutions are found, where serendipity is likely, and where old ideas find new life" (Arias et al., 2000). It can apply to both personal and collective processes employed by members of a community who are involved in a common endeavor. It can be also viewed as an ability of members of a community to put themselves in the shoes of another's with respect to norms and epistemologies and vice versa, and to be explicit about their own as if they were members of a different community (Kynigos \& Kalogeria, 2012).

Akkerman and Bakker (2011) suggest that boundary crossing can entail creative thinking and learning through the following four mechanisms: (a) identification of a boundary, (b) coordination of activity flow acknowledging diverse sites, (c) reflection on the specificities of two sites and the existence of the boundary between them, and (d) transformation where actors from different sites engage in some constructive activity by crossing boundaries and addressing boundary objects. The first mechanism, identification, is about constructing and reconstructing boundaries. It reflects meaning-oriented processes about own and others' perspectives and identities. The other three mechanisms are more about transcending boundaries. Coordination is about creating cooperative and routinized exchanges between practices, while reflection is about expanding one's perspectives on the practices. Transformation involves the co-development of (new) practices. The categorization of the four mechanisms raises the question of how they relate to one another. Several things can be said about this.

\section{TEACHING RESOURCES AS BOUNDARY OBJECTS FACILITATING TEACHERS' CREATIVITY AND LEARNING}

According to Akkerman and Bakker (2011), boundary crossing mechanisms and processes are mediated by 'boundary objects'. Star and Griesemer (1989) first introduced the notion of 'boundary 
objects' as "objects which are both plastic enough to adapt to local needs and the constraints of the several parties employing them, yet robust enough to maintain a common identity across sites. They are weakly structured in common use, and become strongly structured in individual use. These objects may be abstract or concrete. They have different meanings in different social worlds but their structure is common enough to more than one world to make them recognisable, a means of translation (Star \& Griesemer, 1989, p. 393). Boundary objects, being either tools, artifacts, people, discourses, concepts or other 'things', can thus become 'bridges' or 'anchors' between 'intersecting social worlds' and facilitate boundary crossing procedures, and consequently social creativity. In our case, we can easily consider a digital resource under development as a boundary object.

Boundary objects can thus operate as 'resources' for communication and interdisciplinary collaboration between different actors working together towards a shared goal, to help them mitigate the existing 'barriers' and the challenges involved, but also to integrate the different perspectives in new and more creative ideas and products (Fischer, 2013). Boundary objects become "forms of reification, around which communities can organize their interconnections" (Wenger, 1998, p. 105), while, while at the same time they can give way to the creation of new resources. This is particularly relevant to education and educational design activity, a central aspect of teaching practice, in which resources play a central role.

Teaching and learning with resources is the core idea of the Documentational approach in the education sector, developed by Gueudet and Trouche (2009). Here, 'resources' are understood as mediational objects, around which teachers' documentation work is directed and structured. In other words, the teachers' work outside the classroom is led by activities such as searching for, appropriating, transforming and sharing resources, or tasks such as designing learning tasks, planning their succession, or managing time and available artifacts. According to Adler (2000) resources in teachers practice extend beyond material objects (i.e., chalkboard, calculators, computers, textbooks, software, etc.) to encompass human resources (i.e., a teacher's knowledge base) and cultural resources (such as time and language). A'resourced teacher' is a teacher acting with material and socio-cultural resources and not simply a teacher surrounded by material resources. This view is very much in line with what Remillard (2005) points as 'curriculum use as participation with the text', emphasizing not only how teachers engage with, use, shape, adapt, and interpret curriculum materials but also how teachers learn and change from the use of these resources. Documentational approach (Gueudet \& Trouche, 2012) further extends this view of resources by talking about 'a resource system' including all 'things' belonging to the teachers' documentation work: discussions between teachers, orally or online, students' worksheets, a textbook, a piece of software, or "things" that interfere with the teaching activity, such as a student's reaction.

Another central concept in the approach by Gueudet \& Trouche (2012) is the 'documentational genesis' process, through which different kinds of interactions (between teachers and resources, between teachers and students, between teachers and colleagues, between teachers and digital media) take place. "When members of a 'community of practice' or a 'community of interest' participate in such processes a collective resource system is developed. It is actually through 
collective documentational geneses and out of the boundary crossing interactions between the members of a community of teachers-as-educational-designers, working together with various 'resources' as boundary objects for the design of new teaching and learning resources, that boundary crossing creativity can be nurtured.

To round things up, we used Documentational approach as a lens that allowed us to study and recognize educational professionals as resource designers and the resources as objects designed for diverse uses in educational practice. We then engineered diverse designer communities of interest to jointly produce novel resources for use in a transformational educational setting. We studied boundary crossing creativity as the boundary crossing processes developed between individuals comprising a Col socio-technical environment. We viewed creativity as a essential ability to be both employed and fostered by an appropriate approach to the problem at hand, namely how to integrate wicked problems in education (Daskolia \& Kynigos, 2012; Daskolia et al., 2016; Daskolia et al., 2018), taking the climate change issue as a prominent example. So, our intent was to elicit and study boundary crossing creativity in educational design as one way to leverage educational transformation and as a contribution to climate change education.

These considerations open a new line of thought on the role of teaching resources as 'boundary objects' in the genesis of creative ideas and on the technologies and tools that facilitate boundary crossing creativity among educational designers (Glăveanu et al., 2020). They also involve considering new teaching resources as the creative products of these processes in a particular socio-technical environment. Personal resources can be examined in terms of what teachers bring to their out-of-field teaching as well as what they are missing. They can also take the form of professional development support tools for enhancing teachers' disciplinary knowledge or boosting their ability to innovate, to learn and to develop new identities in their teaching practice. Along this line of thought, educational scenarios and activity plans as well as digital artefacts have been designed and used to purposefully operate as 'boundary objects' for teachers in in-service training courses and other professional development programs (i.e., Kynigos \& Kalogeria, 2012; Daskolia et al., 2018).

\section{BOUNDARY CROSSING CREATIVITY IN THE DESIGN OF EDUCATIONAL RESOURCES ON 'WICKED’ SUSTAINABILITY PROBLEMS}

Creativity based on the boundary crossing processes among various actors is reckoned as a necessary competence for addressing wicked problems. Designing educational resources for such problems is complex in itself involving an extension beyond the boundaries of any particular knowledge domain. The inherent complexity of design problems asks for the integration between individual and social creativity as facilitated in boundary crossing situations. Interdisciplinary collaboration among professionals with various backgrounds and expertise is therefore a necessary prerequisite for addressing such problems. The role of creativity in educational design has been only recently acknowledged (Clinton \& Hokanson, 2012), and the same applies to the social dimension of 
educational designers' work and the development of their creative capacity (Daskolia et al., 2016; Daskolia et al., 2018; Kynigos \& Kolovou, 2018).

Although educational design appears at first sight to be an orderly, structured and wellorganized practice, different approaches to it emphasize that it is actually a problem-solving procedure. For example, some view it as a process of solving instructional problems by systematic analysis of the conditions for learning (Seels \& Glasgow, 1998), while others describe it as a predefined linear sequence of progressive steps (Gustafson \& Branch, 2002) or a system of spaces (Brown, 2008). Nevertheless, recent approaches adopt more realistic views emphasizing the messy and iterative nature of the actual design work and the fact that educational designers come across a multitude of 'wicked problems' in their everyday design practices (Thofson, 2010).

'Wicked problems' are real problems faced by communities, groups or individuals, that are ill-defined and dynamic as their parameters are continually in flux (Rittel, 1973; Coyne, 2005). By referring to some dysfunctionality within a complex system (Conklin, 2005), wicked problems are difficult to contain and structure and are interdependent and interconnected. Complexity stems from their multifaceted character and the need to apply various perspectives to grasp them more holistically. However, the very idea of naming a problem as 'wicked' is related to the inability of conventional policies and practices to address the complexities of their multiple and dynamic causes, consequences, their limited predictability and the uncertainty of many different possible solutions.

Current global sustainability challenges, such as climate change, are complex mixtures of global, local, ecological, political, economic and social dynamics (Incropera, 2015). Understanding and identifying all the inherent perspectives and the multitude of interconnected phenomena requires new strategies of learning and thinking (Daskolia \& Kynigos, 2012). They all share the characteristics of 'wicked problems': they are complex, ambiguous and contested issues, with no single solutions and drenched in conflicts of interest among multiple stakeholders (Gibson \& Fox, 2013; Wals, 2015). Complexity stems from their multifaceted character and the need to apply various perspectives to grasp them holistically. They also carry a great deal of indeterminacy and different interpretations may lead to different implementations based on the context and situation. As a consequence, inherent uncertainty and indeterminacy raise feelings of powerlessness, apathy and withdrawal.

Climate change is among the most representative examples of 'wicked problems'. Although scientifically apparent, it is difficult to describe in all its dimensions or to predict its consequences on a local and global level (Incropera, 2015). It is also a problem that cannot be solved with only scientific knowledge or linear and analytical ways of thinking (Kagawa \& Selby, 2010). Fragmentary and subject-oriented scientific knowledge and dualistic frames of thinking are not appropriate to guide problem-solving strategies about climate change (Lehtonen et al., 2019). At the same time, although it is important to develop awareness and action competence on such issues both on an individual and collective level (Cantor et al., 2015), the fact of framing them as 'wicked problems' makes people, especially the young ones, feel overwhelmed and discouraged to get involved with 
(Lazarus, 2009; Hulme, 2009). This also applies to education, with both students and teachers feeling distressed and reluctant to engage with complex environmental problems, especially global ones, such as climate change (Sharp et al., 2021).

However, it is the very nature of climate change that renders it an educational challenge. One inherent difficulty in addressing climate change as a wicked problem is related to the fact that traditional scientific thinking and inquiring approaches have been built on epistemological assumptions aiming to moderate complexity and to minimize uncertainties in the world (Lehtonen et al., 2019). However, 'normal science' paradigms (Kuhn, 1962), supported by appropriate conceptual modes of representing reality, narrow down the focus of their inquiry within the boundaries of close-ended disciplinary fields to address carefully defined (but eventually simplified) 'problems', with the aim to generate valid and generalizable evidence-based knowledge to feed decisionmaking. Normal science frames of thinking have also deeply permeated education, encouraging knowledge engagement through mono-disciplinary domains. However, when it comes to wicked issues such as climate change, disciplinary fragmentation lacks the capacity to allow integrated understanding (O'Brien et al., 2013).

To counteract these shortcomings, 'post-normal science' has emerged as an alternative paradigm of scientific inquiry and knowledge (Funtowicz \& Ravetz, 1993). Drawing on epistemological principles recognizing uncertainty, value-laden agency, and context-specificity as intrinsic attributes of contemporary complex issues, post-normal science promotes inter- and trans-disciplinarity as new frames of understanding the world. Sustainability issues and climate change in particular are characteristic examples where the application of post-normal lenses and processes are required, such as the co-creation of diverse types of knowledge, and the employment of participatory methods, designs, and tools, that allow the emergence of multiple representations and reflection to take place.

We argue for a paradigm shift in education, which stems from the need to move from addressing current sustainability challenges, such as climate change, as siloed problems, to viewing them through post-normal approaches as 'wicked problems' (Lehtonen et al., 2019). Learning engagement with 'wicked problems' requires thus the use of integrated and interdisciplinary perspectives for a holistic and systemic understanding of how real world issues work. New kinds of theoretical concepts are necessary along with empathetic understanding of people's perspectives and localities (Lehtonen et al., 2019). To this end, teaching practice and the design of educational resources about topics of this kind have to be built in inter- and trans-disciplinary approaches (Palmer et al., 2009), to promote skills and competences such as collaborative, creative, and higher order thinking processes that transcends discipline boundaries, and to contribute to the generation of new knowledge and new resolutions for more democratic and socially engaging sustainable development practices.

Different methods and social processes can support the co-creation of knowledge and the exploration of alternative futures to better understand the inherent complexity of wicked problems such as climate change, the implications of different social choices and the consequences 
of different visions and actions in the world (Drenth et al., 2017). Using 'wicked problems' as the focus of learning in the context of authentic learning tasks or inquiry-based learning activities is also proposed by Murgatroyd (2010) as one way to teach critical thinking, design, innovation and creativity in schools.

Teaching about 'wicked problems' is a challenging endeavor for teachers too. The teachers' role is moved from the idea of being solely 'instructors' to becoming facilitators, knowledge brokers and designers of authentic learning experiences and problem-solving, as well as instructors. To do so they need to be able to create new and appropriate educational resources or adapt the resources of others. They also have to leave aside textbooks and focus on learning as a process of finding relevant knowledge and developing new understandings so as to respond to wicked problems and challenges. This is a powerful role imbued with new professional skills and competences, among which creativity. To foster creativity in the role of teachers as designers of educational resources for wicked problems necessitates embedding and supporting their educational design practice in hybrid socio-technical contexts, where interdisciplinary groups of teachers are encouraged to join their disciplinary perspectives and pedagogical content background and expertise to this end. Aided by the use of conceptual and technological tools and boundary crossing creativity processes in educational design activities, post-normal approaches can arise to address and deal with climate change as a wicked problem (Dilon, 2016; König \& Ravetz, 2017).

\section{THE STUDY CONTEXT}

The study presented here explores boundary crossing creativity as manifested in the design of a digital educational resource (a c-book, c- for creativity) on climate change by an interdisciplinary group of Greek teachers and educational stakeholders. The task assigned to the group was the elaboration of a digital resource for teaching and learning about climate change that would foster creative learning in secondary school students by interweaving mathematical concepts and thinking processes while identifying and analysing various dimensions of the climate change issue, and by promoting the students' active engagement and experimentation with them.

Six educational designers were invited to participate in the task. They were teachers with diverse disciplinary background and expertise, such as in mathematics, mathematics education, environmental education, drama in education and the design of digital tools for math education (see Table 1). 
Table 1. Profiles of the educational designers who participated in the design of the Climate Change c-book and their role in it

\begin{tabular}{|c|c|c|c|}
\hline & Pseudo-name & Profile & Role in the design task \\
\hline 1 & Sophia & $\begin{array}{l}\text { Secondary education math teacher, post-doc } \\
\text { researcher, developer and teacher educator in } \\
\text { mathematics teaching with digital resources }\end{array}$ & $\begin{array}{l}\text { Design of widget instances, suggesting or } \\
\text { developing ideas, writing text, reviewing }\end{array}$ \\
\hline 2 & Stephen & $\begin{array}{l}\text { Secondary education math teacher with an MSc in } \\
\text { math education }\end{array}$ & $\begin{array}{l}\text { Design of widget instances, suggesting or } \\
\text { developing ideas, writing text, reviewing }\end{array}$ \\
\hline 3 & Peter & $\begin{array}{l}\text { Senior academic researcher in environmental } \\
\text { education }\end{array}$ & $\begin{array}{l}\text { Suggesting or developing ideas from an } \\
\text { environmental and sustainability perspective, } \\
\text { working on the script, reviewing }\end{array}$ \\
\hline 4 & Christina & $\begin{array}{l}\text { Secondary education teacher in foreign languages, } \\
\text { MSc in environmental education }\end{array}$ & $\begin{array}{l}\text { Suggesting or developing ideas from an } \\
\text { environmental perspective, working on the script, } \\
\text { writing text }\end{array}$ \\
\hline 5 & Helen & $\begin{array}{l}\text { Primary education teacher, post-doc researcher in } \\
\text { math education }\end{array}$ & $\begin{array}{l}\text { Suggesting or developing ideas, writing text, } \\
\text { reviewing, editing }\end{array}$ \\
\hline 6 & Cynthia & $\begin{array}{l}\text { Primary education teacher, MA in drama } \\
\text { education, doctoral student in online education }\end{array}$ & $\begin{array}{l}\text { Suggesting or developing ideas, working on the } \\
\text { script, reviewing }\end{array}$ \\
\hline
\end{tabular}

The group's collaborative design activity took place in a technological infrastructure that was developed in the context of the MCSquared European project (http://www.mc2-project.eu/), and consisted of two workspaces:

(a) 'ColCode', a mindmap tool for organized asynchronous discussions with compulsory metadata pertaining to the creativity aspects of the interaction process. This tool also allowed participants to rate the creative potential of each of the ideas they offered to the design task by using the criteria of 'novelty', 'appropriateness' and 'usability' (on a yes/no basis). As a result of these ratings, ideas could be classified according to an aggregated creativity score (Daskolia et al., 2018).

(b) The 'C-book authoring tool', a technological environment designed to incorporate text with dynamic and configurable widget instances accompanied by corresponding narratives. Educational designers were able to produce textual documents, to attach links and files and to develop widget instances from a set of available tools. For example, MaLT2, a programmable tool to create 3D figural models, is a widget factory, and a microworld of this factory is a widget instance (Kynigos \& Grizioti, 2018). This environment offered also a space for prospective students to engage with the c-book (the 'C-book player').

Joint work for the design and production of the c-book lasted for 4 months (from March to July 2015). Collaboration activity commenced with one face-to-face meeting of all members of the group. 
Overall, 270 contributions were posted in the ColCode workspace and 87 e-mails were exchanged along the course of the work. Moreover, eighteen widget instances were designed by the group of educational designers and integrated in the Climate Change c-book script.

\section{THE CLIMATE CHANGE C-BOOK}

More specifically, the c-book comprised two sections: (a) 'The Living Earth' section, focusing on the causes and effects of climate change (in 17 pages), and (b) 'Making the Impossible Possible' section, addressing human role in inducing and enhancing climate change and practical solutions to reduce its impact (in 8 pages).

The story narrated in the Climate Change c-book is about a 12-year-old boy, George, who lives in an island in the Pacific Ocean. After becoming a climate change refugee, George gets into a journey around the world to set up a youth movement against climate change using social media. George comes across several facets of climate change and becomes aware of the causes (the greenhouse gases) and consequences of it (global warming, melting of the ice sheets, rise of the sea levels, etc.), and the impact of various human activities on raising the levels of carbon dioxide emissions.

The proposed pedagogical use of the Climate Change c-book as a teaching resource is to engage prospective students with various facets of the climate change issue through mathematical concepts, which either 'emerge' along the deployment of the story or are 'discovered' by students while reading it. Among others the c-book investigates the causes and effects of global warming with the computation of the carbon footprint in everyday lifestyle choices, the shapes of an iceberg and a water molecule, the relationship between volume and temperature in water, etc. Students are prompted to experiment and tinker with widget instances to explore correlations between variables, estimate mathematical models, construct and interpret multiple representations, design 3D shapes, make and investigate assumptions, draw and extend conclusions related to climate change dimensions, etc. They are also challenged to establish connections between various representations of a concept (e.g., they are asked to depict and compare $\mathrm{CO}_{2}$ emissions by drawing circles and disks) or to handle open problems (e.g., they use relevant information to estimate footprint values).

Students can work in pairs or participate in whole-class discussions orchestrated by the teacher to present their ideas and proposed solutions, to justify their arguments and discuss about the different strategies they elaborated to address the interconnected facets of climate change as a wicked problem. The teacher can also use the c-book to introduce new mathematical concepts (e.g., the linear correlation of two variables), or to apply math concepts in environmental phenomena and processes underlying the climate change issue.

The Climate Change c-book provides students with many opportunities to establish connections between various representations of climate change: to represent visual information about temperature rise by graphs, to depict $\mathrm{CO}_{2}$ emissions by drawing circles and disks, to construct 
graphical representations of functions, and to create a visual water molecule model by modifying logo commands. Two more embedded features of the educational resource are interactivity and autonomous learning. The students can manipulate variables or try out their own constructions and observe the results of their activity. They can also follow the orderly sequence of the designed activities or go back and forth between the pages of the c-book and work on the learning activities in a non-linear fashion based on their interests and the level of their mathematical competence. The c-book's flexibility in its pedagogical use is also demonstrated in the fact that several tasks are open-ended and can be extended or further elaborated. For example, the modelling of carbon footprint can become more precise with the students collecting additional or their own data. In this sense, one student can construct his/her own model and another student can later take it and reflect on it or improve it by constructing a new or more effective one. Finally, the narrative allows for different possible developments of the story depending on the students' activity. Their elaborated models can lead them to formulate new questions, which might affect the direction of the whole story plot.

\section{RESEARCH DESIGN}

In this paper, we present and discuss findings from the analysis of the collaborative design work of six Greek educational designers on the Climate Change c-book. The aim was to understand their collaborative activity in designing the c-book as located in the specific socio-technical environment, by identifying 'critical episodes' depicting the boundary crossing processes and the use of boundary objects that enabled creativity till the actual realization of the c-book.

A qualitative methodological design was adopted as part of a naturalistic inquiry using a case study approach. The six educational designers who took part in the collaborative design of the Climate Change c-book were the study's participants and their interactions while designing the cbook became the focus of analysis. The data collected were the 270 contributions uploaded in the ColCode workspace during the 3-months period of the educational design process, which were extracted as transcripts in a MS Excel form.

Data analysis was performed in a sequence of iterative procedures. The transcripts were first analyzed line by line and an open-substantive coding was performed as to the main processes, decisions and moves taken by the participants during their shared design work. Then, the researchers proceeded to narrowing down the data on selected critical episodes, i.e., identified sequences of communications and related modifications in the resources, which signified the manifestation of instances of boundary-crossing creativity. A set of selected critical episodes were then used to elaborate our interpretation of how the communicative actions generated creative processes. The episode selection was thus a representative corpus for descriptive codification based on the study's research questions. The episodes were then subjected to more focused analysis, based on 
codes extracted through a mixed (inductive and deductive) analytical procedure. The following research questions guided the analysis of the transcripts in the selected episodes:

- What boundary-crossing mechanisms are employed in the interactions among the educational designers and with the technologies used during the design process of the Climate Change c-book?

- How do boundary crossing interactions between educational designers with a different disciplinary domain (i.e., mathematics vs. environmental education teachers) affect their creative performance?

- What elements of the c-book design have been addressed as 'boundary objects' by the teachers in the course of their design work?

In this paper we present and analyze two critical episodes illustrating how creativity in theeducational design process of the Climate Change $\mathrm{c}$-book has been facilitated by boundary crossing processes and boundary objects exchanged between the designers.

\section{Critical episode 1: Studying the interrelation between narratives and widgets in the process of designing the c-book}

The first selected episode (Figure 1) took place two months after the outset of the design process. Its duration was 18 days (24/5-10/6/2015). Interaction data drawn from ColCode (Figure 2) show that the episode was located at a peak period of the designers' joint work. The episode focuses on social creativity processes related to Col members' decisions on how to interweave the narratives with the widget instances into a coherent whole in the Climate change c-book.

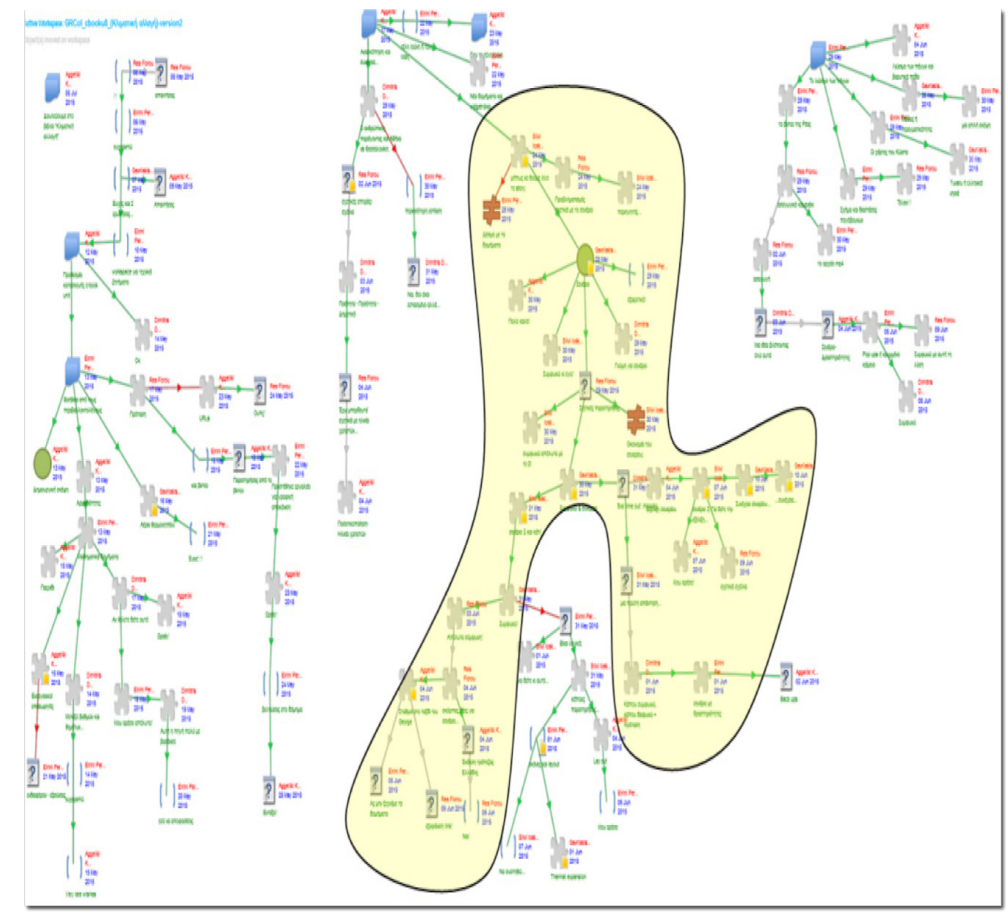

Figure 1. Depiction of critical episode 1 in ColCode 
All educational designers of the Climate Change c-book are involved in this episode. The discussion is taking place at the second stage of the design process, during which certain ideas about the educational design (widget instances and corresponding learning activities) and about the narrative are being put into use by the designers. At that time, a number of instances designed to afford mathematical creativity took the role of boundary objects as they progressively evolved in consecutive cycles. However, a decision on the narrative that would incorporate and join together these elements was pending, despite the fact that some interesting ideas had been already suggested. Thus, the analysis of the present episode aims to shed light into how the designers' conceptions about their productions in terms of educational design (widget instances and corresponding learning activities) intertwined with their ideas about the narrative of the c-book unit.

The discussion begins with a suggestion on the outline of the scenario based on an earlier idea proposed by Christina about the main character, a backpacker who travels around the globe facing the impact of climate change. Cynthia (24/5/15) attaches a document where she describes the story plot in consecutive stages: how to set the scene, how to introduce the problem, how to build the action, and how to come up to its resolution. She comments that her suggestions will enable the designers group to come up with a story outline and asks for the team's feedback. Christina (24/5/15) responds by appraising the creative potential in Cynthia's idea. However, she thinks that it diverges from her own original idea. Two days later, Sophia (26/5/15) expressed her reservations about the outline proposed by Cynthia. She thinks it is inconsistent with what has been already discussed among them in terms of educational design. She says: "I don't get this story. I don't understand how it connects to the widget instances and the research questions we posed in the c-book. [...] Whoever writes the story has to have a good grasp of the structure and the activities."

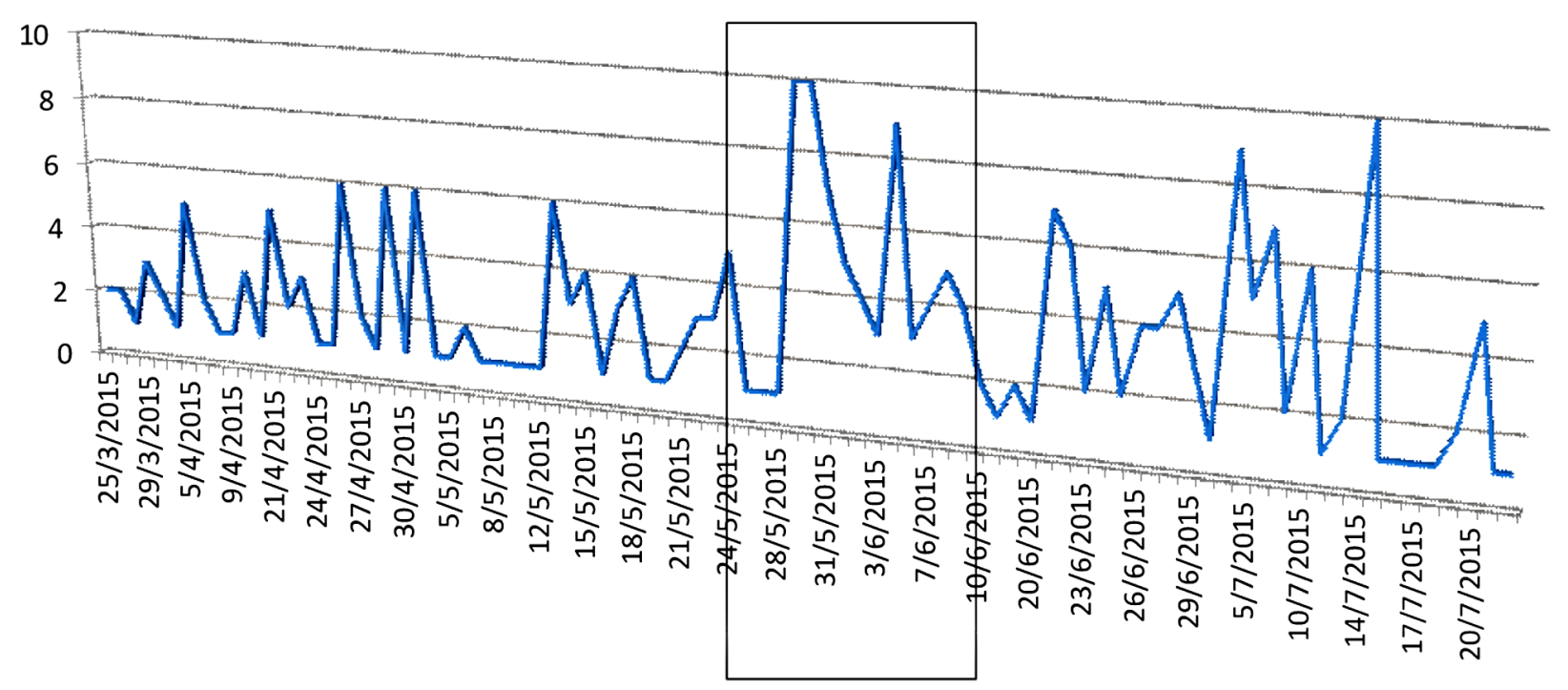

Figure 2. Degree of interaction between educational designers in critical episode 1 
Peter (28/5/15) replies to Sophia's post by attaching a document in which he describes his idea of a new story. He says: "...Trying to connect all the widget instances, I thought of starting writing a story based on a real incidence. Shall we go on like this?" This idea became yet a boundary object, since it was unanimously accepted as novel and as an intriguing narrative with the potential to incorporate and interconnect all previously suggested widgets instances: the story's main character, a 12-yearold boy, who is inhabitant of an island nation in the Pacific Ocean and is forced to flee his homeland and become an environmental refugee. During his journey around the world he tries to set up a youth movement against climate change based on the use of social media.

In the next days the script, which is written collaboratively by Peter and Cynthia, develops quickly through consecutive versions. In the course of this activity, Stephen (31/5/15) sends a post in which he expresses reservations about the relationship between the widget instances and the narrative. He thinks that none of them has priority over the other, and that the widget instances and the narrative should co-evolve. Yet, he is not sure whether the widget instance he designed (calculating and comparing the carbon footprint of two cities) could be incorporated into Peter's version, since its main character comes from a different cultural background than the one suggested by the widget instance.

Peter (31/5/15) responds immediately to Stephen underlining that it is important to show how the western way of thinking plays a crucial role, since climate change is caused by the first world countries but affects the whole planet. Besides, the flexibility of the script as such allows several twists and turns to several directions and in this sense the inclusion of that widget instance would not be problematic. Cynthia (31/5/15) reacts to this view by suggesting enriching the story with new characters, who will convey the global north frame of thinking on environmental issues. A few days later (7/7/15), she posts a supplement of the script in which George, the main character, visits Greece and witnesses the consequences of people's everyday practices on $\mathrm{CO}_{2}$ emissions.

\section{Analysis}

This episode illustrates how boundary crossing processes among the six Greek educational designers enhanced their creative thinking about how to interweave the narrative with the widget instances. Starting with the identification of a barrier from the part of Sophia, when she reacts strongly to Cynthia's proposal about the script, pushes her to define more clearly for the whole group what fits in their shared practice of designing a c-book: the narrative should take into account the widget instances that have been already developed and interweave them in its plot. This boundary crossing mechanism is activated by an expert educational designer with a background in math education towards a novice designer and newcomer to the group, Cynthia, with a background in creative writing, who is not yet familiar with the shared norms and values of the group. Sophia's reaction fuels the process of identification which leads to re-establishing a core characteristic of a c-book, the meshing of narratives with the widgets. Stephen's point builds on this reaction in an attempt to coordinate the two perspectives to the benefit of the whole task, by stating that the narratives and the widget instances should actually co-evolve, setting the tone for a more creative conception of the c-book. 
This communicative connection is further established around the idea of the narrative as an evolving artifact that bridges two diverse disciplinary and educational domains (mathematics and environmental education). This is more apparent in Peter's actual attempt to build up a narrative that will unify the existing widget instances into an organic whole. Continuity and effortless movement between the perspectives is becoming the norm of interaction. Boundary permeability is enhanced since math education designers are getting involved into the construction of the narrative, while environmental educators get into interconnecting mathematical concepts to climate change aspects in consecutive versions of the script. These boundary crossing reflective processes of perspective-making and perspective-taking were proved essential for the interweavement of the widgets instances with the narratives into a concise whole.

Several refined versions of the script followed these dense interactions between the educational designers and served as boundary objects that facilitated the communication and coordination of the designers' diverse perspectives. The flexibility of the script allowed its customization to new ideas about the educational design; and vice versa, it enabled the modification of the widget instances already developed or inspired the design of new ones. Creativity in the collaborative design of the c-book was facilitated by these boundary crossing exchanges among the educational designers and led to the transformation of the initial ideas into tangible products.

\section{Critical episode 2: The design of a widget instance as a result of the creative interaction between mathematicians and environmental educators}

The second episode (Figure 3) started one month after the outset of the design process, it lasted 8 days (26/4-3/5/2015) and participants in it were three designers: Peter, Christina and Helen. It was actually the exchange between these three which resulted into Sophia's idea to design a new widget instance, although her own contribution to this actual episode is marginal. Interaction data drawn from ColCode (see, Figure 3) show that the episode took place at a peak period of the team's work.

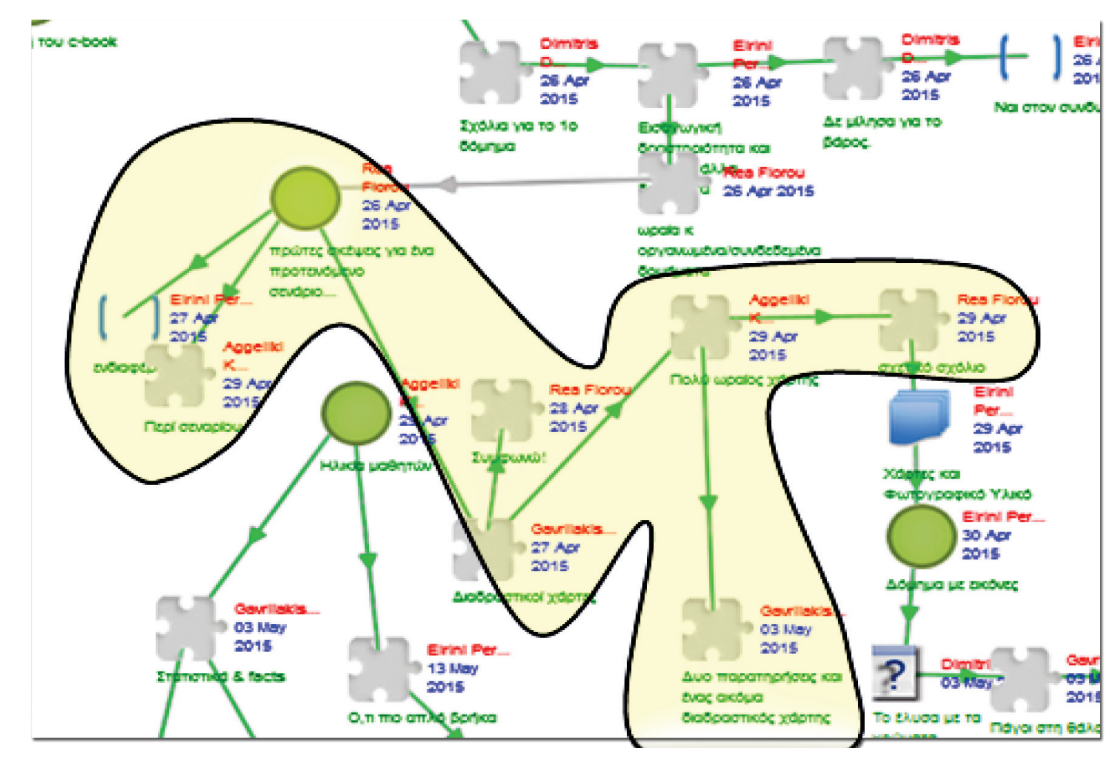

Figure 3. Depiction of critical episode 2 in ColCode 
The episode is located at the beginning of the second stage of the design process, when the technical implementation of ideas takes place. It begins with a new idea that was put forth by Christina in relation to the narrative of the c-book. Christina (26/4/15) says: [...] "I was thinking that to approach climate change on a global scale our main character could be an adventurous traveler (a backpacker) who wanders around the world and comes across the manifestations and impacts of climate change." Sophia's (27/4/15) response was that she liked the idea and invited the other designers to ponder on it.

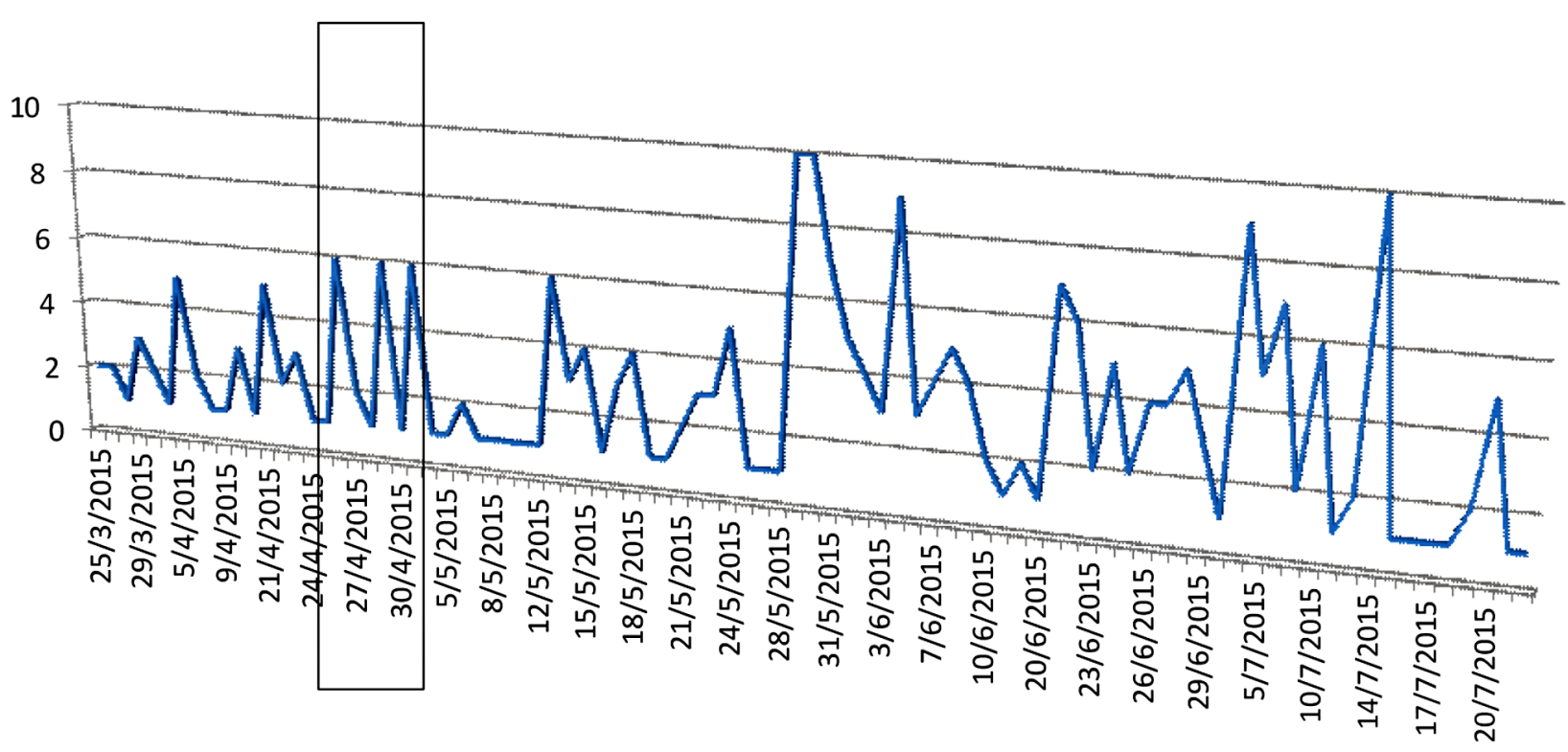

Figure 4. Degree of interaction between educational designers in critical episode 2

The idea was actually immediately taken up by other designers who started contributing to it with posts about links to interactive maps depicting the consequences of climate change or portraying different aspects of it (e.g., the relation between industrialization and greenhouse gas emissions). Peter (27/4/15) commented that he also liked the idea and that students would find it appealing too ("Adventure and travelling are attractive topics to kids of all ages"). He went on by saying that he attached the links of two interactive maps to explain what he had in mind. Christina (28/4/15) responded with enthusiasm and she pointed out that these maps can serve as tools for the whole team but also for the students to study climate change. She thought that they fit perfectly to her idea.

Helen (29/4/15) then attached a link to another interactive map with circles depicting global carbon footprints inequality between developing countries, like China, who have become major emitters, while a large share of their emissions comes from the production of goods to be consumed in countries of the western world. Following this post, Christina (29/4/15) refered to 'environmental racism', a term coined to describe such inequalities.

However, it is Sophia who comes later on to pick up all the ideas shared and to suggest the design of a new widget instance allowing the visualization of the $\mathrm{CO}_{2}$ emissions. Her idea was 
that the students would draw circles on a map to depict the footprint of two main Greek cities. This new idea was then taken up and realized by Stephen who designed a new widget instance based on it.

\section{Analysis}

This episode depicts how the collective resource system of this group of designers is enriched through the sharing, reflection, and transformation of individual resources. These resources operate as boundary objects that enable not only communication and interdisciplinary collaboration between educational designers with different disciplinary backgrounds but also help them mitigate the existing barriers and address the challenges involved in creative ways. They become 'bridges' between the intersecting worlds of the designers and facilitate boundary crossing procedures, and consequently creativity.

Peter's interactive map, which he shared with the other designers, serves this function: it incorporates Christina's idea on the plot and provides an example of how to proceed. The idea is picked up by Helen who adapts it to an alternative use of interactive maps, to illustrate some more social aspects of climate change. In this way she attempts to establish a common space of communication between the intersecting fields of math and environmental education and this is why she shares new boundary objects of this kind. Searching for resources in a domain other than her own becomes a way to re-define her identity through an identification boundary crossing process.

A communicative connection between the environmental and the mathematical perspective is thus established. The interactive maps take a different meaning and use as boundary objects across the diverse perspectives: for environmental education designers, maps are tools that depict climate change impacts, whereas for math educators maps could serve as tools to represent and compare phenomena in numerical sizes and mathematical relations. The maps as boundary objects enabled the coordination of activity so that both CoPs cooperated efficiently in the technical implementation of the carbon footprint depiction idea. An external resource has thus taken a mediational role between diverse perspectives and later was reified as a widget instance in the c-book. Sophia, an experienced widget developer, functions as boundary broker by suggesting a novel utilization of the interactive maps that bridges the environmental with the mathematical perspective.

\section{CONCLUDING REMARKS: CREATIVITY IN THE BOUNDARY CROSSINGS OF DIVERSE EDUCATIONAL DESIGNER GROUPS}

In this study we explored how creativity arises in boundary crossing interaction between educational designers with a different disciplinary background who are collaboratively working in a joint task, to design teaching resources addressing the wicked problem of climate change. Our 
study's findings showed that interdisciplinary communities of practice aided by and in interaction with appropriate technologies can function as an empowered professional development milieu, within which creative processes and outcomes can be nurtured and paradigm shifts can occur.

The critical episode analysis performed addressed the following questions: a) what were the boundary crossing mechanisms employed in the design of the Climate Change c-book teaching resource? b) what was the effect of the boundary crossing interactions between math and environmental education designers? and c) what elements of the educational design of the c-book have been dealt as boundary objects and how? The educational designers, along with trying to frame climate change as a wicked problem, attempted to address the challenging issue of designing a creative educational resource on this topic. Identification as a boundary crossing mechanism was employed to help them frame the task itself by expressing and sharing their individual perspectives on how to tackle the various challenges involved.

On the other hand, perspective making and taking allowed them to expand their view and collaboratively conceive the narratives of the c-book and the widget instances as a creative interplay between the two. It is noteworthy that throughout the c-book design the widget instances and the narratives have co-evolved. Both the consecutive versions of the widget instances and the narratives were employed as boundary objects, not only in the sense that they facilitated communication and collaboration between the designers, but also by coordinating their prevalent perspectives in an interdisciplinary teaching resource. It was the sharing, negotiation, and refinement of the resources among diverse educational designers that ascribed the function of boundary objects to the resources for enabling creativity apart from communication among the designers.

Based on our research, we suggest that supporting boundary crossing creativity in interdisciplinary teams of educational designers can be an answer not only to how to focus learning on addressing the grand wicked problems of our times, but also how to deal with the multiple challenges arising from educational design per se. Creativity, together with collaboration and problem-solving, are highlighted as key meta-knowledge competences that need to be fostered to empower youths to address current sustainability challenges. They are pointed to as cornerstones for efficient professional performance and development in the 21st century. Teachers' practice, and especially the design of educational resources as one of its facets, are two fields where these competences and dispositions have to be boosted to support the transition to new ways of thinking and learning for a more sustainable world.

Our study's findings align with this new conception of teaching, in which teachers operate not only as instructors but as educational designers of creative learning experiences for their students. Teachers are trained to serve a system considering education to predominantly afford a silo academic domain approach and the mechanism to support student learning as a task of addressing current major socio-scientific issues as one-solution problems, which can be easily and fully grasped and handled. We suggest that helping students grapple with wicked problems is in that sense a wicked pedagogical problem in itself. The core idea we present here is that among the most challenging 'wicked problems' encountered by educational designers is how to use 'wicked 
problems' as the focus of learning for their students (Daskolia \& Kynigos, 2012; Daskolia et al., 2012; Lehtonen et al., 2019; Murgatroyd, 2010) and as one way to teach critical thinking, design, innovation and creativity in school-based contexts. Without underestimating or lowering the importance of educators' disciplinary expertise, our view emphasizes interdisciplinary collaboration in designing learning environments and resources with the use of appropriate digital tools and technologies with a focus on cultivating problem-solving, critical and creative thinking approaches towards current current sustainability challenges (Daskolia \& Kynigos, 2012; Daskolia et al., 2012; Lehtonen et al., 2019; Murgatroyd, 2010). To bring forth innovation and creativity in education, teaching as a profession needs to be strengthened in communities where different disciplinary background and pedagogical content knowledge is merged to creative designs of learning (Glăveanu \& Beghetto, 2017; Glăveanu, et al., 2020).

\section{References}

Adler, J. (2000). Conceptualising resources as a theme for teacher education. Journal of Mathematics Teacher Education, 3(3), 205-224.

Akkerman, S.F., \& Bakker, A. (2011). Boundary Crossing and Boundary Objects. Review of Educational Research, 81(2), 132-169.

Arias, E., Eden, H., Fischer, G., Gorman, A., \& Scharff, E. (2000). Transcending the individual human mindcreating shared understanding through collaborative design. ACM Transactions on Computer-Human Interaction (TOCHI), 7(1), 84-113.

Bakker, A., \& Akkerman, S. F. (2014). A boundary-crossing approach to support students' integration of statistical and work-related knowledge. Educational Studies in Mathematics, 86(2), 223-237.

Brown, T. (2008). Design thinking. Harvard Business Review, 86(6), 85-92.

Cantor, A., DeLauer, V., Martin, D., \& Rogan, J. (2015). Training interdisciplinary “wicked problem" solvers: Applying lessons from HERO in community-based research experiences for undergraduates. Journal of Geography in Higher Education, 39(3), 407-419.

Clinton, G., \& Hokanson, B. (2012). Creativity in the training and practice of instructional designers: the Design/Creativity Loops model. Educational Technology Research and Development, 60(1), 111-130.

Conklin, J. (2005). Dialogue mapping: Building shared understanding of wicked problems. New Jersey: John Wiley \& Sons, Inc.

Coyne, R. (2005). Wicked problems revisited. Design Studies, 26, 5-17.

Darbellay, F., Moody, Z., \& Lubart, T. (Eds.) (2017). Creativity, design thinking and interdisciplinarity. Springer: Singapore.

Daskolia, M., \& Kynigos, C. (2012). Applying a Constructionist Frame to Learning about Sustainability. Creative Education, 3, 818-823. https://www.scirp.org/html/23538.html

Daskolia, M., Dimos, A., Kampylis, P. (2012). Secondary teachers' conceptions of creative thinking within the context of Environmental Education. International Journal of Environmental and Science Education, 7(2), 269-290. https://files.eric.ed.gov/fulltext/EJ990520.pdf

Daskolia, M., Kolovou, A., \& Kynigos, C. (2016). Social creativity in the design of digital Resources. Interweaving math with environmental education the case study of the Climate Change C-book CSEDU 2016. In Proceedings of the $8^{\text {th }}$ International Conference on Computer Supported Education (vol. 1, pp. 134-143). Rome, Italy: Scitepress. https://doi.org/10.5220/0005810101340143

Daskolia M., Kynigos C., Kolovou A. (2018). Addressing Creativity in the Collaborative Design of Digital Books for Environmental and Math Education. In T. Mikropoulos (Ed.), Research on e-Learning and ICT in Education (pp. 69-86). Springer, Cham. https://doi.org/10.1007/978-3-319-95059-4_4 
Drenth, D., Elahi, S., König, A. (2017). Exploring alternative futures with scenarios. In A. König, \& J. Ravetz, (Eds.), Sustainability science: Key issues (pp. 113-132). Routledge.

Engeström, Y. (2001). Expansive learning at work: Toward an activity theoretical reconceptualization. Journal of Education and Work, 14(1), 133-156.

Engeström, Y., Engeström, R., \& Kärkkäinen, M. (1995). Polycontextuality and boundary crossing in expert cognition: Learning and problem solving in complex work activities. Learning and Instruction, 5, 319336.

Fischer, G. (2004). Social creativity: turning barriers into opportunities for collaborative design. In Proceedings of the $8^{\text {th }}$ Conference on Participatory Design "Artful integration: Interweaving Media, Materials and Practices" (vol. 1, pp. 152-161).

Fischer, G. (2005). Distances and diversity: sources for social creativity. In Proceedings of the $5^{\text {th }}$ Conference on Creativity \& Cognition (pp. 128-136).

Fischer, G. (2013). Social creativity and cultures of participation: Bringing cultures of creativity alive. Billund: The LEGO Foundation. Available from: www.legofoundation.com

Fischer, G., Giaccardi, E., Eden, H., Sugimoto, M., \& Ye, Y. (2005). Beyond binary choices: Integrating individual and social creativity. International Journal of Human-Computer Studies, 63(4-5), 482-512.

Funtowicz S.O., \& Ravetz J.R. (1993). The Emergence of Post-Normal Science. In R. Von Schomberg (Ed.), Science, Politics and Morality. Theory and Decision Library (Series A: Philosophy and Methodology of the Social Sciences) (vol. 17, pp. 85-123). Springer: Dordrecht. https://doi.org/10.1007/978-94-015-8143-1_6

Gibson R., \& Fox M. (2013). Simple, Complex and Wicked Problems. Available from http://mofox.com/pdf/ simple,complex,wicked.pdf

Glăveanu, V. (2015). Creativity as a Sociocultural Act. Journal of Creative Behavior, 49(3), 165-180. https://doi. org/10.1002/jocb.94

Glăveanu, V.P. (2020). A sociocultural theory of creativity: Bridging the social, the material, and the psychological. Review of General Psychology, 24(4), 335-354.

Glăveanu, V.P. \& Beghetto, R.A. (2017). The difference that makes a 'creative' difference in education. In R.A. Beghetto \& B. Sriraman (Eds.), Creative Contradictions in Education (pp. 37-54). Cham: Springer.

Glăveanu, V.P., Ness, I.J., \& de Saint Laurent, C. (2020). Creativity, Learning and Technology: Opportunities, Challenges and New Horizons. Creativity Research Journal, 32(1), 1-3. https://doi.org/10.1080/1040041 9.2020.1712167

Gueudet, G., \& Trouche, L. (2009). Towards new documentation systems for mathematics teachers? Educational Studies in Mathematics, 71(3), 199-218.

Gueudet, G., \& Trouche, L. (2012). Teachers' work with resources: Documentational geneses and professional geneses. In G. Gueudet, B. Pepin, \& L. Trouche (Eds.), From text to 'lived'resources: Mathematics curriculum materials and teacher development (pp. 189-213). New York: Springer.

Gustafson, K.L., \& Branch, R.M. (2002). What is instructional design? In R.A. Reiser, \& J.V. Dempsey (Eds.), Trends and Issues in Instructional Design and Technology (pp. 333-343). Upper Saddle River, NY: Merrill Prentice Hall.

Hansen, G., \& Stone, D. (2016). Assessing the observed impact of anthropogenic climate change. Nature Climate Change, 6(5), 532-537.

Hulme, M. (2009). Why we disagree about climate change: Understanding controversy, inaction and opportunity. Cambridge: Cambridge University Press. https://doi.org/10.1017/CBO9780511841200

John-Steiner, V. (2000). Creative collaboration. New York: Oxford University Press.

Incropera, F.P. (2015). Climate Change: A Wicked Problem - Complexity and Uncertainly at the Intersection of Science, Economics, Politics and Human Behaviour. Cambridge: Cambridge University Press.

Kagawa, F., \& Selby, D. (Eds.). (2010). Education and Climate Change: Living and Learning in Interesting Times. Routledge. 
Kereluik, K., Mishra, P., Fahnoe, C., \& Terry, L. (2013). What knowledge is of most worth: Teacher knowledge for 21st century learning. Journal of Digital Learning in Teacher Education, 29(4), 127-140.

Kynigos, C., \& Kalogeria, E. (2012). Boundary crossing through in-service online mathematics teacher education: the case of scenarios and half-baked microworlds. ZDM, 44(6), 733-745.

Kynigos, C., \& Kolovou, A. (2018). Teachers as designers of digital educational resources for creative mathematical thinking. In L. Fan, L. Trouche, C. Qi, S. Rezat, J. Visnovska (Eds.), Research on Mathematics Textbooks and Teachers' Resources (pp. 145-164). Springer, Cham., https://doi.org/10.1007/978-3-31973253-4_7

Lave, J. \& Wenger, E. (1991). Situated learning. Cambridge: Cambridge University Press.

Lazarus, R. (2009). Super Wicked Problems and Climate Change: Restraining the Present to Liberate the Future. Cornell Law Review, 94(5), 1153-1233.

Lehtonen, A., Salonen, A.O., \& Cantell, H. (2019). Climate change education: A new approach for a world of wicked problems. In J.W. Cook (Ed.), Sustainability, Human Well-Being, and the Future of Education (pp. 339-374). Palgrave Macmillan, Cham., https://doi.org/10.1007/978-3-319-78580-6_11

Murgatroyd, S. (2010). Wicked problems' and the work of the school. European Journal of Education, 45(2), 259-279.

Newman-Storen, R. (2014). Leadership in sustainability: Creating an interface between creativity and leadership theory in dealing with "Wicked Problems". Sustainability, 6(9), 5955-5967.

O'Brien, L., Marzano, M. \& White, R.M. (2013). "Participatory interdisciplinarity": Towards the integration of disciplinary diversity with stakeholder engagement for new models of knowledge production. Science and Public Policy, 40(1), 51-61. doi: 10.1093/scipol/scs120

Palmer, J.M., Smith, T., Willetts, J.R., \& Mitchell, C.A. (2009). Creativity, ethics and transformation: Key factors in a transdisciplinary application of systems methodology to resolving wicked problems in sustainability. Systemic development: Local solutions in a global environment, 1, 69-71.

Remillard, J.T. (2005). Examining key concepts in research on teachers' use of mathematics curricula. Review of Educational Research, 75(2), 211-246.

Rittel, H.W.J., \& Webber, M. (1973). Dilemmas in a general theory of planning. Policy Sciences, 4(2), 155-169.

Seels, B.A., \& Glasgow, Z. (1998). Making instructional design decisions (2nd ed.). Columbus, OH: Merrill Publishing Co.

Sharp, E.L., Fagan, J., Kah, M., McEntee, M., \& Salmond, J. (2021). Hopeful approaches to teaching and learning environmental "wicked problems". Journal of Geography in Higher Education, 1-19, https://doi.org/ 10.1080/03098265.2021.1900081

Star, S.L. (1989). The structure of ill-structured solutions: Boundary objects and heterogeneous distributed problem solving. In L. Gasser \& M.N. Huhns (Eds.), Distributed artificial intelligence (pp. 37-54). San Mateo: Kaufmann Inc.

Star, S.L., \& Griesemer, J.R. (1989). Institutional ecology, translations and boundary objects: Amateurs and professionals in Berkeley's Museum of Vertebrate Zoology, 1907-39. Social Studies of Science, 19(3), 387-420.

Thofson, K.K.H. (2010). The wicked problem and the instructional designer: Recognition of and approaches to wicked problems in instructional design practice. Doctoral dissertation, Capella University.

UNESCO (2017). Changing Minds, not the Climate: The Role of Education. Paris: UNESCO.

Wals, A.E. (2015). Beyond unreasonable doubt. Education and learning for socio-ecological sustainability in the Anthropocene. Wageningen University.

Wenger, E. (1998). Communities of practice: Learning as a social system. Systems Thinker, 9(5), 2-3.

(c) Copyright by Faculty of Education, University of Bialystok, 20 Swierkowa St., 15-328 Bialystok, Poland tel. +48857457283

e-mail: creativity@uwb.edu.pl

http://www.creativity.uwb.edu.pl 